\title{
Hermenêutica e Foucault: A CRIAÇÃO DE MODOS DE RESISTÊNCIA E REEXISTÊNCIA
}

\author{
Maria Cláudia Dal'Igna* \\ José Pascoal Mantovani**
}

\begin{abstract}
RESUMO
Este trabalho, apresentado em forma de ensaio filosófico e pedagógico, propõe experimentar outros modos de escrever e interpretar os conceitos de Michel Foucault. Para desenvolver a analítica, parte-se de três conceitos basilares: saber (arqueologia), poder (genealogia) e subjetividade (arqueogenealogia). A tese que se instaura é que a interpretação ocorre na articulação entre movimentos recíprocos de interioridade e exterioridade do sujeito - constituídos pelos discursos, pelos jogos de poder e pelas tecnologias de si - que, para significar o mundo, dão nomes e sentidos à existência. Como resultado, propõe-se pensar a hermenêutica foucaultiana como transgressora, não pelo seu caráter subversivo, mas pela possibilidade de funcionar como ferramenta teórica e metodológica. Interpretar é, nessa perspectiva, projetar o espaço-outro, o tempo-outro e a vida-outra, indagando o impacto da crise anti-intelectualista e negacionista. Palavras-chave: Michel Foucault. Hermenêutica. Arqueologia. Genealogia. Subjetividade.
\end{abstract}

* Doutora e Mestra em Educação. Graduada em Pedagogia. Professora dos cursos de Licenciatura e do PPG em Educação da Universidade do Vale do Rio dos Sinos - UNISINOS. Pesquisadora do Grupo Interinstitucional em Docências, Pedagogias e Diferenças (GIPEDI/UNISINOS/CNPq) e do Grupo de Estudos de Educação e Relações de Gênero (GEERGE/UFRGS/CNPq).

** Graduado em Teologia, Filosofia e Pedagogia, Mestre em Ciências da Religião, Doutor em Educação. Docente do Ensino Básico e Superior. Coordena o Grupo de Estudos DOMAINES: Foucault em perspectiva. 


\title{
HERMENEUTICS AND FOUCAULT: THE CREATION OF RESISTANCE AND RE-EXISTENCE MODES
}

\begin{abstract}
This work, presented in the form of a philosophical and pedagogical essay, proposes to experiment other ways of writing and interpreting Michel Foucault's concepts. In order to develop the analytics, three basic concepts are started: knowledge (archaeology), power (genealogy) and subjectivity (archaeogenealogy). The established thesis is that the interpretation takes place in the articulation between reciprocal movements of interiority and exteriority of the subject - constituted by discourses, the power relations and the technologies of the self - who, in order to signify the world, give names and, thus, the meaning for existence. As a result, the paper proposes to think of Foucault's hermeneutics as a transgressor, not because of its subversive character, but because of the possibility of functioning as a theoretical and methodological tool. Interpreting, in this perspective, is to project the other-space, the other-time and the other-life, inquiring the impact of the anti-intellectualist and denial crisis.
\end{abstract}

Key Words: Michel Foucault. Hermeneutics. Archeology. Genealogy. Subjectivity.

\section{INTRODUÇÃo}

"Existe estupro culposo. Vacina para covid-19 causa aids. Índios são culturalmente atrasados. A pessoa preta é exótica”. Afirmações nesta direção têm se revelado cada vez mais comuns na atualidade. A crise anti-intelectualista e negacionista tem estabelecido a tônica da atualidade conhecida como pós-verdade ${ }^{1}$. Perdeu-se a dimensão da diferença entre o que é crime e o que é opinião. As informações em

1 Ao analisar a produção de subjetividades contemporâneas, Christian Dunker (2017, p. 38) explica que o que podemos compreender como pós-verdade envolve uma "[...] combinação calculada de observações corretas, interpretações plausíveis e fontes confiáveis em uma mistura que é, no conjunto, absolutamente falsa e interesseira". Na perspectiva do autor, o conceito de pós-verdade também está implicado com a recusa do outro, pois em uma cultura cada vez mais acelerada, individualista e concorrencial, quando o sujeito se sente ameaçado, reage com ódio ou violência. Trata-se de uma busca incessante pela regulação da vida por meio da completude e das certezas.

Revista Páginas de Filosofia, v. 10, n. 1, p.195-208, jan.-jun. 2021 
destaque possibilitam vasta interpretação da Contemporaneidade e de seus fenômenos, mas qualquer possibilidade de interpretação implica em estranhamento, em questionamento. Nesta perspectiva, três assertivas são apresentadas: (1) certezas não precisam de interpretação; (2) a verdade rejeita qualquer sombra de dúvidas; (3) todo espectro absolutista é unidimensional e restringe qualquer silhueta ficcional.

Estas afirmações são lentes valiosas para a leitura do contemporâneo. Isto porque vivemos a ditadura da certeza, a qual, em linhas gerais, não passa de "doxa" vulgar, opiniões fincadas em falácias e sofismas; tempos de inquisição a qualquer espírito crítico e que provoque ou gere dúvidas, ao passo que a verdade, cristalizada, está prescrita e é normativa. Além disto, também é um período marcado pelo despotismo democrático, caracterizado por seu viés impositivo, arbitrário e castrador, que ilude o sujeito com a falsa sensação de liberdade, a qual é tolhida à medida que supostas escolhas individuais não passam de mimetismos sociais. Em suma, as subjetividades são objetivadas e objetificadas. As cadeias não precisam ser de ferro quando a capacidade interpretativa (hermenêutica) está docilizada.

Por outro lado, ao exercitar nossos pensamentos e tensionar as próprias reflexões aqui expostas, a partir das contribuições de Friedrich Nietzsche (2001; 2002), Michel Foucault (2005a; 2005b), Scarlett Marton (2010) e Judith Butler (2009; 2015), defendemos que, para pensar a atualidade e os acontecimentos que eclodem na cotidianidade, é fundamental ter a própria vida vivida como base ontológica. Esse gesto de interrogar-se sobre a atualidade é o que Foucault (2005a) denomina de "ontologia do presente" ou "ontologia crítica de nós mesmos" 2 .

É preciso considerar a ontologia crítica de nós mesmos não certamente como uma teoria, uma doutrina, nem mesmo como um corpo permanente de saber que se acumula; é preciso concebê-la como uma atitude, um ethos, uma via filosófica em que a crítica do que somos é

2 Esta é uma evidente raiz nietzschiana. Marton (2010), estudiosa do pensamento do filósofo, ao analisar as contribuições de Nietzsche e seu modo de interrogar a vida e a si mesmo, explica que seu pensamento é desconstrutivo, um filósofo da suspeita, um filosofar a marteladas que questiona os conceitos construídos com base na moral e na razão ocidentais. 
simultaneamente análise histórica dos limites que nos são colocados e prova sua ultrapassagem possível (FOUCAULT, 2005a, p. 351).

Trata-se de uma atitude crítica que permite interrogar o que somos e como nos tornamos o que somos. É a análise da constituição das nossas subjetividades. Retomando as ideias apresentadas anteriormente, compreendemos que Foucault (2018) permite construir um gesto de interrogação dos modos de subjetivação contemporâneos para identificar dispositivos de saber e de poder implicados com a naturalização e a banalização das violências e dos abusos, ao mesmo tempo em que permite propor novas formas de luta e de resistência ${ }^{3}$.

Para desenvolver nossa analítica, partiremos de três conceitos basilares em Foucault: saber (arqueologia), poder (genealogia) e subjetividade (arqueogenealogia) em articulação aos modos como nos constituímos sujeitos pelos discursos (arqueologia dos saberes), pelos jogos de poder (genealogia dos poderes) e pelas tecnologias de si.

Nesta perspectiva, este artigo, apresentado em forma de ensaio filosófico e pedagógico, propõe experimentar modos outros de escrever e interpretar os conceitos foucaultianos ${ }^{4}$. Theodor Adorno (2003, p. 30 ), ao analisar o gênero textual ensaio, propõe que ele "[...] não apenas negligência a certeza indubitável, como também renuncia ao ideal dessa certeza. Torna-se verdadeiro pela marcha de seu pensamento, que o leva para além de si mesmo, e não pela obsessão em buscar seus fundamentos como se fossem tesouros enterrados".

Com isso, explicamos que não será nosso esforço interpretar nenhum dos elementos destacados anteriormente. Em vez disso, pretendemos apresentar ferramentas para interpretar e problematizar as

3 Para pensar a ideia de resistência, mobilizamos o pensamento de Butler (2017, p. 218), fundamentado em parte na filosofia foucaultiana: "se resistir é dar lugar a um novo modo de vida, a uma vida mais vivível que se oponha à distribuição diferenciada da precariedade, então os atos de resistência serão uma forma de dizer não a um modo de vida que ao mesmo tempo diz sim a outro modo distinto" (tradução nossa).

4 As marcas deste ensaio estão relacionadas a nossas posições de sujeito homem e mulher, um filósofo e uma pedagoga, um pai e uma mãe, ambos docentes e pesquisadores da educação básica e superior. 
realidades, bem como seus fenômenos para fomentar outros horizontes. A atualidade desta tríade - saber (arqueologia), poder (genealogia) e subjetividade (arqueogenealogia) - está fincada na premissa que interpretar é projetar o espaço-outro, o tempo-outro e a vida-outra.

Por um lado, Foucault se ocupa de estabelecer as condições histórico-epistêmicas das diferentes concepções da interpretação; especialmente, da interpretação durante o Renascimento e no século XIX. 0 objetivo desse trabalho é levar a cabo a arqueologia das ciências humanas. Por outro lado, a arqueologia como método de análise histórica quer ser uma forma de análise que se distancia dos pressupostos e dos procedimentos da hermenêutica (CASTRO, 2016, p. 230).

Seguindo as proposições de Edgardo Castro, Foucault (2002) problematiza a interpretação ao propor que interpretar é distinção ou modelação. Se a distinção se articula com a noção de estabelecer semelhanças e diferenças, bem como estruturar a cartografia das assimilações possíveis que permeiam o fenômeno, a noção de modelação, por sua vez, tangencia a ideia de que tanto a hermenêutica como a exegese têm como pressuposto desvendar o que está escondido. A proposta de Foucault (2002), ao que se refere à interpretação/hermenêutica, não é seguir a síndrome adâmica da correspondência, o clássico nominalismo em determinar, classificar e conjugar, no sentido aristotélico, o que é ou o que não é. A proposta foucaultiana é deparar-se com o interstício entre interpretação e formalização, ater-se ao hiato entre dar nome à coisa, classificá-la e interpretá-la.

O que propomos como interpretação e hermenêutica neste artigo a partir de e com Foucault, é a ideia de que interpretar e diagnosticar em sua base encontra-se na arqueologia do saber. A interpretação, nesta perspectiva, está sujeita ao/à intérprete que não define a coisa, mas sua experiência da coisa. Em seu livro "A hermenêutica do sujeito" (FOUCAULT, 2018), o termo "hermenêutica" não aparece nenhuma vez. Tal proposição está relacionada à ideia de que o ato de interpretar está intimamente ligado ao intérprete. Foucault (2018) destaca o processo de conhecimento de si. Seu ponto de partida está no texto platônico "Alcibíades Primeiro" em que o enredo segue os conselhos de Sócrates ao jovem Alcibíades que se prepara para a vida política. 
A proposta da hermenêutica é o ato contínuo de ficção de si, de invenções de si, do desdobrar sobre si. A hermenêutica do sujeito não é a veridicção ou consolidação do que se interpreta por verdade. A hermenêutica está ligada aos modos pelos quais o/a intérprete chega à determinada possibilidade da verdade. Isto é, a verdade não é estática, mas perspectiva em movimento. Esta compreensão consolida a proposição de que a constituição do sujeito não está limitada à cristalização da hermenêutica do/a intérprete. Todo ato de interpretar está vulnerável a novos paradigmas e jogos de verdade. Interpretar é ficcionar, criar e transgredir.

Desta forma, nosso empreendimento crítico pode contribuir (é o que desejamos) para questionar, a partir de determinadas realidades, quais mudanças são possíveis, quais mudanças são desejáveis e como construir essas mudanças. Para tanto, apresentaremos as categorias foucaultianas - arqueologia, genealogia e subjetividade - como ferramentas úteis para a atitude interpretativa.

\section{Arqueologia, genealogia e subjetividade}

0 pensamento de Foucault é multifacetado e complexo. Sua produção acadêmica é ampla, transita desde ensaios filosóficos, resenhas críticas, entrevistas e comentários gerais a livros e cursos. É comum organizarmos sua obra em três grandes eixos, o que permite identificar determinados temas em destaque em cada período ${ }^{5}$.

Ainda que isso possa parecer uma simplificação, vamos propor um modo de exposição embasado nos três conceitos já mencionados (arqueologia, genealogia e subjetividade), os quais também podem ser identificados como temas centrais de cada eixo.

A arqueologia é "uma história das condições históricas de possibilidade do ser. Essas dependeriam da experiência desnuda da ordem e de seus modos de ser" (CASTRO, 2016, p. 40). Foucault (2005b) afasta-se da história tradicional (suas continuidades, causas, tipologias), para

\footnotetext{
Não estamos considerando aqui um período fenomenológico - marcado pelas contribuições de Martin Heidegger, Maurice Merleau-Ponty, Ludwig Biswanger, entre outros, para analisar os trabalhos de Foucault. Nesta direção, sugerimos o trabalho de Marcos Nalli (2006).
} 
analisar as rupturas, as descontinuidades, as disjunções verificadas na história, mais nas distinções entre as várias épocas do que nas semelhanças. Trata-se de embrenhar-se no interior de qualquer regime discursivo, a fim de estabelecer as regras internas e as condições de emergência de determinadas práticas.

Como já referimos, o esforço não é desvelar o que é a verdade, mas percorrer o caminho que estabeleceu o que se entende por verdade como verdade. Nesta perspectiva, destacamos alguns pontos importantes: (1) a arqueologia não está em busca das invenções ou do momento em que algo foi dito pela primeira vez, mas da regularidade dos enunciados; (2) a arqueologia busca manter as múltiplas asperezas que constituem a história; (3) a arqueologia quer mostrar como a história pode dar lugar a tipos definidos de discursos; (4) a arqueologia destaca que as rupturas são consideradas como os fenômenos de clivagem dos regimes gerais, dos tempos ou períodos. A arqueologia é a maneira do sujeito olhar para a história sem ficar refém do historicismo, das datas ou das grandes narrativas. "Como qualquer método original, a arqueologia tem seu objetivo próprio, a saber, práticas discursivas e não discursivas [...]" (FLYNN, 2016, p. 51). A construção deste mosaico está intrinsicamente ligada aos procedimentos de controle, seleção, organização e redistribuição da produção dos discursos (regras) que sustentam saberes-práticas de objetivação e de subjetivação.

De outro modo, examinar o eixo genealógico nos possibilita problematizar a noção de poder que, em linhas gerais, pode ser definido como estrutura de relação (relações entre indivíduos e instituições), como destaca Foucault (2008, p. 78):

não existe poder como substância, ou o poder não é uma propriedade monopolizada por uma classe social, ou o poder não é uma espécie de capacidade que seria produzida por um aparelho como o Estado. $\mathrm{Na}$ realidade, existem relações de poder, relações entre pessoas, isto é, entre os agentes, onde um e outro, uns e outros, estão em posições diferentes, assimétricas. [...] quando dizemos que o poder é relação, isto significa que existem dois termos, o que significa que a modificação de um dos dois termos, mudará a relação. Ou seja, longe de constituir um tipo de estrutura prisional, o poder é uma rede de relacionamentos, móvel, cambiante, modificável e com frequência frágil. 
Por mais que não exista uma teoria sobre o poder em Foucault (2008), a ideia de mobilidade que ele apregoa sobre este conceito auxilia na ampliação da hermenêutica dos acontecimentos cotidianos e na própria constituição do sujeito. Em linhas gerais, pode-se dizer que, a partir dos textos "Vigiar e punir" (FOUCAULT, 2000) e "História da sexualidade I" (FOUCAULT, 1999): (1) as relações de poder não são nem manifestação de um consenso nem a renúncia à liberdade (ainda que não possam superá-los); (2) as relações de poder, ainda que distintas das capacidades e das relações de comunicações, estão entrelaçadas com elas. Quando as capacidades, as relações de comunicação e as relações de poder se ajustam umas às outras, segundo fórmulas reflexas e explícitas, encontramos uma disciplina; (3) as relações de poder são conjuntos de ações que têm por objeto outras ações possíveis (ação sobre ação), apenas sobre um campo de possibilidades, induzem, separam, facilitam, dificultam, estendem, limitam, impendem; (4) as relações de poder estão ligadas às condutas. 0 exercício do poder consiste em conduzir condutas e dispor probabilidades (corpo-indivíduo e corpo-população); (5) o poder se exerce apenas sobre sujeitos livres, sujeitos que dispõem de um campo de várias condutas possíveis. Quando as determinações estão separadas, não podemos falar em relação de poder, mas em relações de violência ${ }^{6}$.

Se a síntese da arqueologia está em torno do caminho sobre o que se entende por verdade e a genealogia se atém às constituições primárias das relações de poder que governam os sujeitos, a subjetividade é "a maneira pela qual o sujeito faz a experiência de si mesmo num jogo de verdade, no qual ele se relaciona consigo mesmo" (FOUCAULT, 2005b, p. 236). Para agir sobre a própria subjetividade, é necessário transformar pensamentos e desejos do indivíduo em objetos de inspeção e de regulação.

Os modos de subjetivação estão ligados com a noção de ética, ou seja, o processo constitutivo de si, o qual é distinto da ideia de moral que está atrelada a normas, condutas, leis e costumes estabelecidos.

6 Sobre poder, dominação e violência, a partir de Foucault, ver Alfredo Veiga-Neto (2006). A respeito destes conceitos, em articulação com os estudos de Foucault e Butler, ver André Silva, Dagmar Meyer e Roberta Riegel (2021). 
Em categorias foucaultianas, a ética é a coragem do sujeito em se relacionar consigo, questionando as prescrições estabelecidas pela moral.

A subjetividade não é concebida a partir de uma teoria prévia e universal do sujeito, não é relacionada com uma experiência originária ou fundadora, não é relacionada com uma antropologia que tenha um valor universal. A subjetividade é concebida como o que se constitui e se transforma na relação que ela tem com sua própria verdade. Não há teoria do sujeito independente da relação com a verdade (FOUCAULT, 2019, p. 13).

De acordo com o autor, a subjetividade é um "conjunto de processos de subjetivação aos quais os indivíduos foram submetidos ou que aplicaram com relação a si mesmos" (FOUCAULT, 2019, p. 255). A subjetividade é o meio pelo qual o sujeito se apropria das verdades que emergem em suas experiências, é o viés marcado pela singularidade empírica do acontecimento e, simultaneamente, pela partilha de vivências.

Por mais didático que seja apresentar os períodos distintos, um dos caminhos mais significativos da interpretação da obra de Foucault é partir da articulação entre diacronias e sincronias, ou seja, perceber a relação das partes do texto com o todo da obra. Com este movimento, se estabelecem domínios e mudanças de ênfase que organizam a reflexão, sem limitar as possibilidades e transgressões que o instrumental foucaultiano proporciona. Assim como aponta Johanna Oksala (2011, p. 10), "as três fases não se referem a três diferentes métodos ou objetos de estudo. 0 que marcou o início de cada 'nova' fase foi a introdução de um novo eixo de análise, que resultou numa visão mais abrangente".

As ideias de que gostaria de falar aqui não se podem enquadrar nem na teoria nem na metodologia. Gostaria de inicialmente dizer qual foi o objetivo do meu trabalho nos últimos vinte anos. Não foi o de analisar os fenômenos do poder, nem de lançar as bases para uma tal análise. Procurei acima de tudo produzir uma história dos diferentes modos de subjetivação do ser humano na nossa cultura; tratei, nessa óptica, dos três modos de objetivação que transformam os seres humanos em sujeitos. Existem, em primeiro lugar, os diferentes modos de investigação que procuram aceder ao estatuto de ciência; estou a pensar, por exemplo, na objetivação do sujeito falante na gramática geral, na 
filologia e na linguística. Ou também, sempre neste primeiro modo, na objetivação do sujeito produtivo, do sujeito que produz, em economia e na análise das riquezas. Ou ainda, para tomar um terceiro exemplo, na objetivação devida ao simples fato de existir na vida, na história natural ou na biologia. Na segunda parte do meu trabalho, estudei a objetivação do sujeito naquilo que designarei de "práticas divergentes". 0 sujeito quer dividido no interior dele mesmo, quer dividido dos outros. Este processo faz dele um objeto. As partilhas entre o louco e o homem são de espírito, o doente e o indivíduo com boa saúde, o criminoso e o "bem-comportado" ilustra esta tendência. Enfim, tenho procurado estudar - é esse o meu trabalho em curso - a maneira como um ser humano se transforma em sujeito; tenho orientado minhas pesquisas na direção da sexualidade, por exemplo - a maneira como o ser humano tem aprendido a reconhecer-se como sujeito de uma "sexualidade". Não é, portanto, o poder, mas o sujeito, que constitui o tema geral das minhas investigações. (grifos nossos). (FOUCAULT, 1995, p. 231-232).

Como procuramos mostrar anteriormente e, considerando a análise do próprio Foucault sobre sua obra, a tríade saber (arqueologia), poder (genealogia) e subjetividade (arqueogenealogia) tem um ponto em comum: o sujeito. Com todos os riscos que isso implica, propomos a seguinte estrutura didática:

\begin{tabular}{|l|l|l|}
\hline \multicolumn{1}{|c|}{ ARQUEOLOGIA } & \multicolumn{1}{|c|}{ GENEALOGIA } & ARQUEOGENEALOGIA \\
\hline \multicolumn{1}{|c|}{ SABER } & \multicolumn{1}{|c|}{ PODER } & \multicolumn{1}{c|}{ SI/subjetividade } \\
\hline $\begin{array}{l}\text { Como nos constituímos } \\
\text { como sujeitos pelo } \\
\text { saber? }\end{array}$ & $\begin{array}{l}\text { Como nos constituímos } \\
\text { como sujeitos pela } \\
\text { ação de uns sobre os } \\
\text { outros? }\end{array}$ & $\begin{array}{l}\text { Como nos constituí- } \\
\text { mos como sujeitos } \\
\text { pela ação de cada um } \\
\text { consigo próprio? }\end{array}$ \\
\hline
\end{tabular}

Fonte: Elaborado pelo autor e pela autora.

Em linhas gerais, ao encadearmos saber, poder e subjetividade enfatizamos que as interpelações que o sujeito faz sobre si, seja no âmbito arqueológico (ao indagar sobre as camadas do que se constata como verdade); seja no âmbito genealógico (ao problematizar as relações que o perfazem e o afetam); seja no âmbito arqueogenealógico (ao indagar os alicerces do saber e das relações que o constituem) são 
ações de investigações que buscam respostas, as quais suscitarão novas perguntas. Esta tríade está diretamente entrelaçada com o âmago da atitude filosófica, isto é, existe abertura para as perguntas, as quais são mobilizadoras. As perguntas potencializam o devir ontológico do sujeito. Neste sentido arqueogenealógico, a noção da interpretação como postura transgressiva assume novos paradigmas. Antes de aprofundar nesta temática, vale retomar as três hipóteses do início do texto, porém, lidas pelo viés da proposição arqueogenealógica: (1) certezas são circunstanciais, por isso as contingências destituíram a cristalização de indubitabilidade; (2) ao passo que a verdade está condicionada a perspectivismos, ela se torna a sombra do ceticismo; (3) as tiranias tecnicistas são dissipadas pela singularidade do sujeito que é múltiplo. Interpretar é ação compreensiva e inventiva do indivíduo, tema que trabalharemos a seguir.

\section{HERMENÊUTICA COMO TRANSGRESSÃo}

Para fundamentar a noção da hermenêutica como transgressão, revisitaremos a obra "As palavras e as coisas", em que Foucault (2002, p. 536) destaca que "o homem é uma invenção recente cuja data a arqueologia de nosso pensamento mostra facilmente. E, talvez, o fim próximo". A crítica do autor está em torno da figura do homem universal, da ideia de que há um tipo de homem. Segundo Foucault (2018, p. 85), o homem universal está à beira da extinção, pois a

noção de homem, e no humanismo dos anos 1950, 1960, era a utilização de um universal entendido como universal-noção. Haveria uma natureza humana, haveria necessidades humanas, haveria uma essência humana etc. e é em nome desse universal do homem que faríamos revoluções, aboliríamos a exploração, nacionalizaríamos indústrias, deveríamos nos filiar ao Partido Comunista etc. Este universal que permite muitas coisas e que, ao mesmo tempo, supunha, de maneira ligeiramente ingênua, uma espécie de permanência trans-histórica, sub-histórica ou meta-histórica do homem.

Pode-se afirmar que a universalização do homem, como apresenta Foucault (2018), é imposição idealista, é a arbitrariedade platônica. Assim, é na apresentação de um tipo de verdade, de certeza e 
de arquétipo que se elimina quaisquer outros meios e caminhos de interpretação e investigação do sujeito. Se não há possibilidade de tensão, de contradição ou até mesmo da falseabilidade, o que se impõe não passa de dogmas e do bom ordenamento e organização dos aparelhos prescritivos e instituições de sequestro. Não é preciso pensar em contextos homogeneizados e castrados de sentidos e significados. Não existe interpretação quando não há possibilidade de variação. A característica dos manuais são suas características monossêmicas. Interpretar é aventurar-se em labirintos que não têm como fuga qualquer fio de Ariadne.

A hipótese é que se o resultado está posto previamente, de modo apriorístico, não existe função ou necessidade de qualquer esforço hermenêutico. A tendência algorítmica da Contemporaneidade e o dualismo maniqueísta ideológico lança névoa sobre a potência do ato interpretativo. Interpretar é construir heterotopias, ou seja, é por meio da interpretação que espaços e tempos outros emergem. Em vez de usar o termo utopia - que pressupõe o não lugar, mas identificável - a heterotopia proporciona o lugar que não é identificável, pois é, em sua essência, singular, inédito, único.

Como desdobramento da hipótese acima, destaca-se que a tese que se instaura é que a interpretação ocorre na eclosão de forças centrípetas/centrífugas e endógenas/exógenas constitutivas do sujeito que, para significar e dar sentido ao mundo vivido, se apoia em metáforas vivas. A interpretação ocorre na articulação entre movimentos recíprocos de interioridade e exterioridade do sujeito que, para significar o mundo, dá nomes e, assim, sentido para a existência, de modo que toda mobilidade e transposição é mediada pela metáfora da vida.

Em suma, interpretar é transgredir, é devir que emerge da efração, de sublevação. Para interpretar a Contemporaneidade, é preciso, em primeiro lugar, ater-se à noção de enquadramento que as certezas apresentam, limitando as insurgências e rupturas contextuais. Logo, para interpretar é preciso considerar os limites da própria interpretação. Em segundo lugar, superado a noção de infertilidade hermenêutica e nutrido pela coragem da experimentação interpretativa, a transgressão surgirá não como devaneio, nem como clivagem contingencial. E, em 
terceiro lugar, interpretar é o devir que causa modificação, que é marcado pelo estigma da metamorfose, em que o rompimento das cadeias e muros coercitivos darão lugar ao espaço, ao tempo e à identidade.

Utilizar Foucault como lente interpretativa da Contemporaneidade, é olhar para os dados da pobreza, da discriminação, da violência, da segregação, da higienização social, da manutenção da desigualdade dentre outros fenômenos e interpretá-los não sob o viés ou polo das certezas e verdades, mas sob o viés das impermanências. Interpretar é extrapolar paradigmas para inventar outros modos de vida, existência e reexistência.

\section{REFERÊNCIAS}

ADORNO, T. 0 ensaio como forma. Notas de literatura I. São Paulo: Duas Cidades/ Editora 34, 2003.

BUTLER, J. Quadros de guerra: quando a vida é passível de luto? Rio de Janeiro: Civilização Brasileira, 2009.

BUTLER, J. Relatar a si mesmo: crítica da violência ética. São Paulo: Autêntica, 2015.

BUTLER, J. Cuerpos aliados y lucha política: hacia una teoría performativa de la asamblea. Viejo, María José. Barcelona, Buenos Aires, México: Paidós, 2017.

CASTRO, E. Vocabulário de Foucault: um percurso pelos temas, conceitos e autores. Belo Horizonte: Editora Autêntica, 2016.

DUNKER, C. Subjetividade em tempos de pós-verdade. In: PINTO, M.; LEÃO, M. (Orgs.). Ética e Pós-Verdade. São Paulo: Dublinenses, 2017, v. 1, p. 9-42.

FLYNN, T. O mapeamento da história por Foucault. In.: GUTTING, G. (Org.). Foucault. São Paulo: Editora Ideas \& Letras, 2016.

FOUCAULT, M. Nietzsche, Freud e Marx: theatrum philosoficum. Porto: Anagrama, 1980.

FOUCAULT, M. O sujeito e o poder. In: DREYFUS, H.; RABINOW, P. (Orgs.). Michel Foucault - uma trajetória filosófica: para além do estruturalismo e da hermenêutica. Rio de Janeiro: Forense-Universitária, 1995. p.231-249.

FOUCAULT, M. História da sexualidade I: a vontade de saber. Rio de Janeiro: Graal, 1999.

FOUCAULT, M. Vigiar e punir: nascimento da prisão. Petrópolis: Vozes, 2000.

FOUCAULT, M. As palavras e as coisas: uma arqueologia das ciências humanas. São Paulo: Martins Fontes, 2002.

Revista Páginas de Filosofia, v. 10, n. 1, p. 195-208, jan.-jun. 2021 
FOUCAULT, M. O que são as Luzes? Ditos \& Escritos II: Arqueologia das ciências e história dos sistemas de pensamento. São Paulo: Forense Universitária, 2005a. p.335-351. FOUCAULT, M. Arqueologia do saber. Rio de Janeiro: Forense, 2005b.

FOUCAULT, M. A hermenêutica do sujeito. São Paulo: Martins Fontes, 2018.

FOUCAULT, M. O Enigma da Revolta. São Paulo: N-1 Edição, 2019a.

FOUCAULT, M. Subjetividade e Verdade. São Paulo: Martins Fontes, 2019b.

MARTON, S. Nietzsche, filósofo da suspeita. Rio de Janeiro: Casa da Palavra; São Paulo: Casa do Saber, 2010.

NALLI, M. Foucault e a fenomenologia. São Paulo: Loyola, 2006.

NIETZSCHE, F. A Gaia Ciência. São Paulo: Cia das Letras, 2001.

NIETZSCHE, F. Além de Bem e Mal. São Paulo: Cia das Letras, 2002.

OKSALA, Johanna. Como ler Foucault. Rio de Janeiro: Zahar, 2011.

SILVA, A.; MEYER, D.; RIEGEL, R. Gênero, mulher, crime e violência. Revista Educação em Questão, v. 59, n. 59, p. 1-22, e-124637, jan./mar. 2021.

VEIGA-NETO, A. Dominação, violência, poder e educação escolar em tempos de Império. In: RAGO, Margareth; VEIGA-NETO, Alfredo (Orgs.). Figuras de Foucault. Belo Horizonte: Autêntica, 2006. p.13-38. 